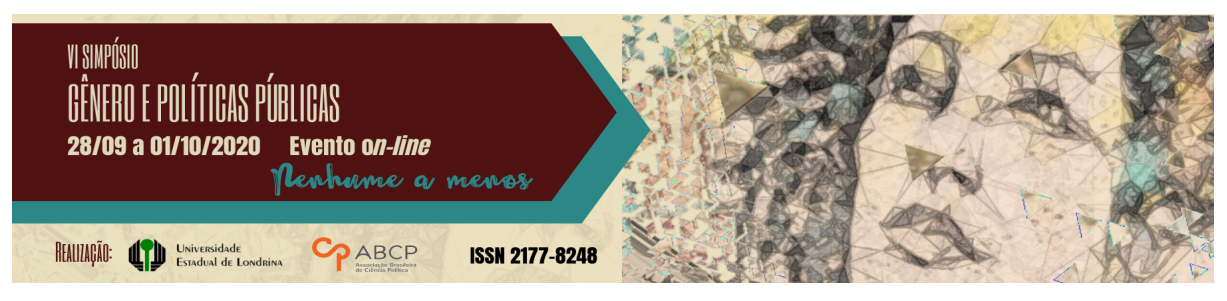

\title{
O retrato de mães jovens: maternidade na adolescência e sua relação com a trajetória escolar
}

\author{
Luana Ribeiro Polido; Silvana Mariano²
}

\begin{abstract}
Resumo
O presente artigo explora o caráter multifacetado das experiências de gravidez e maternidade com mulheres adolescentes em situação de pobreza. A pesquisa teve como objetivo compreender como as conexões entre as experiências escolares e a vivência da maternidade se configuram em determinadas rotas escolares que resultam em baixa escolaridade. A investigação se orientou pela hipótese de que o abandono escolar tem motivações que antecedem a gravidez na adolescência e esta pode, em alguns casos, atuar apenas como desfecho de experiências anteriormente delineadas. As análises são baseadas em interpretações de 6 (seis) casos de mulheres que vivenciaram a gravidez na adolescência, são beneficiárias do Programa Bolsa Família e residentes em Belém (PA), Distrito Federal, Porto Alegre (RS), Salvador (BA) e São Paulo (SP). $\mathrm{O}$ contato com as participantes da pesquisa deu-se com a técnica de entrevistas narrativas interpretadas com a Análise de Conteúdo.
\end{abstract}

Palavras-chave: maternidade adolescente; experiências escolares; desigualdades sociais.

\section{The portrait of young mothers: motherhood while a teenager and its relationship with the school trajectory}

\footnotetext{
${ }^{1}$ Graduanda em Ciências Sociais pela Universidade Estadual de Londrina (UEL). E-mail: luana.ribeiro.polido@uel.br

2 Doutora em Sociologia pela Universidade de Campinas (Unicamp). Professora do Departamento de Ciências

Sociais e do Programa de Pós-Graduação em Sociologia da Universidade Estadual de Londrina (UEL). E-mail: silvanamariano@yahoo.com.br
}

GT 11 - Gênero, políticas de desenvolvimento e combate à pobreza 


\begin{abstract}
This article explores the multifaceted nature of pregnancy and motherhood experiences of teenage girls living in poverty. The research aimed to understand how the connections between school experiences and the experience of motherhood are configured in certain school routes that result in low level of schooling. The investigation was guided by the hypothesis that school dropout has motivations that precede adolescent pregnancy and this may, in some cases, act only as an outcome of previously outlined experiences. The analysis is based on interpretations of 6 cases of women who experienced pregnancy in adolescence and that are beneficiaries of the Federal social programme named Bolsa Família. They are residents of the following cities: Belém (PA), Belo Horizonte (MG), Federal District, Porto Alegre (RS), Salvador (BA) and São Paulo (SP). The contact with the survey participants was made using the technique of narrative interviews interpreted with Contents Analysis.
\end{abstract}

Keywords: Teenage motherhood; school experiences; social inequalities.

\title{
Introdução ${ }^{3}$
}

A vivência da maternidade na adolescência das meninas é tema de preocupação recorrente em diversos setores, atravessando as políticas públicas e os debates políticos, econômicos e sociais. Diferentes discursos por vezes entram em disputa e outras vezes se reforçam mutuamente. Entre eles, os enfoques morais, com concepções lineares e universalizantes sobre as experiências juvenis; enfoques biológicos, com ênfase no quadro de saúde da mulher; e certos enfoques de desenvolvimento humano que enfatizam as perdas que a gravidez na adolescência produz para o desenvolvimento das capacidades das mulheres (MARIANO, 2020). O resultado é a tendência de visões homogeneizadoras sobre a juventude, a centralidade da ótica do risco e das vulnerabilidades e uma visão vitimizadora sobre as adolescentes

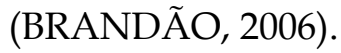

\footnotetext{
3 Agradecemos à Fundação Araucária de Apoio e Desenvolvimento Científico e Tecnológico e ao Conselho Nacional de Desenvolvimento Científico e Tecnológico $(\mathrm{CNPq})$ pelos financiamentos e bolsas que contribuíram para o desenvolvimento desta pesquisa. Agradecemos às integrantes do grupo de pesquisa Gênero e Políticas Públicas (GEPOP), da Universidade Estadual de Londrina (UEL) pelas interlocuções que contribuíram para o enriquecimento deste trabalho.
} 
As perspectivas feministas também entram em disputa com esses discursos e colocam em exame os efeitos diferenciados que a gravidez e a maternidade produzem na condição de vida de moças e de rapazes. Em uma sociedade de acentuadas desigualdades de gênero, como a brasileira, a participação dos rapazes neste fenômeno raramente é referida. Muitos debates são conduzidos como se as mulheres engravidassem sozinhas, seja qual for o ciclo de vida. Ao tratar dos desafios da maternidade, a discussão pública também parece supor que esta é uma responsabilidade exclusivamente feminina. As perspectivas feministas contribuem para evidenciar o caráter social e sociológico do fenômeno. Também evidenciam o problemático deslizamento entre gravidez e maternidade, dado que concretamente uma experiência não pressupõe, necessariamente, a outra (HEILBORN, 2006). Sem aderirmos a visões vitimizadoras, é relevante que tenhamos em consideração que a gravidez na adolescência é um fator crítico para as oportunidades das mulheres (PNUD, 2010).

Existe certo lugar comum que toma a maternidade juvenil como causa da pobreza e, igualmente, um lugar comum que a toma como causa do abandono escolar. Neste trabalho, queremos contribuir para um exame mais cuidadoso sobre esses nexos. As experiências escolares são marcadas por conflitos sociais decorrentes das diversas desigualdades relacionadas a gênero, classe e raça/etnia. Nestes diferentes cenários, nem sempre a experiência escolar é linear, muitas vezes, inclusive, ela se encerra muito cedo, com diversos casos de evasão escolar, que é a realidade de muitos/as jovens brasileiros/as. As adolescências e as juventudes são fases de autonomização e coincidem com o período da escolarização e da experimentação sexual, sendo a socialização afetivo-sexual uma busca da adolescente pela "liberdade" (BRANDÃO; HEIBORN, 2006). Entre as jovens em situação de pobreza, muitas vezes o trabalho doméstico pago ou não pago e as demandas de cuidado de irmãs e irmãos menores, por exemplo, são fatores que influenciam e não deixam uma alternativa, que não a evasão escolar (MARIANO; FERREIRA; TAVARES, 2020). 
Neste trabalho, nos dedicamos a investigar a seguinte questão: como as experiências escolares, os aspectos econômicos anteriores à gravidez e a maternidade na adolescência influenciaram na escolaridade de jovens-mães beneficiarias do Programa Bolsa Família? Tomamos como hipótese que o abandono escolar, na maioria das vezes, tem motivações que antecedem a gravidez na adolescência e esta pode, em alguns casos, atuar apenas como desfecho de uma experiência anteriormente delineada. Condições de trabalho doméstico e cuidado, trabalhos desgastantes física e emocionalmente e baixas expectativas quanto ao retorno da escolaridade contribuem para produzir socialmente o abandono escolar entre as meninas e jovens das camadas pobres. Considerando as interconexões entre os dois temas aqui abordados, este artigo tem como objetivo compreender a experiência de maternidade na adolescência de mulheres em situação de pobreza e sua relação com a escolarização.

Para investigar nossa hipótese, nos dedicamos à análise de 06 (seis) casos de participantes, selecionados da base de dados da pesquisa "Gênero e Interseccionalidades na questão do desenvolvimento: os desafios do Programa Bolsa Família para a quebra do ciclo intergeracional da pobreza". As entrevistas desta base de dados foram realizadas entre abril e dezembro de 2018, com abrangência nacional. Essa pesquisa investigou as condições de autonomia de mulheres em situação de pobreza em grandes centros urbanos no Brasil. A base de dados é composta pelo total de 97 casos, cujas participantes foram mulheres titulares do benefício do Programa Bolsa Família abordadas em Centros de Referência da Assistência Social (CRAS) em Belém (PA), Belo Horizonte (MG), Distrito Federal, Porto Alegre (RS), Salvador (BA) e São Paulo (SP).

Para a seleção dos casos envolvidos neste artigo, consideramos as informantes com até 25 anos de idade, na ocasião das entrevistas, e que relataram ter filhas/os até os 19 anos de idade. Esses recortes etários foram adotados em virtude da definição de adolescência e de juventude do Ministério da Saúde e da Organização Mundial da Saúde (OMS) que compreendem a adolescência dos 10 aos 19 anos e a juventude dos 15 
aos $24 \operatorname{anos}^{4}$ (BRASIL, 2018). Aplicados esses critérios, identificamos 11 (onze) casos de entrevistadas com maternidade na adolescência e, desses, selecionamos 06 (seis) para análise, considerando os casos com maior profundidade nas narrativas ${ }^{5}$. Todas as entrevistadas são apresentadas com nomes fictícios, a fim de preservar o anonimato das participantes da pesquisa.

A construção de dados da pesquisa foi com o uso de entrevistas narrativas, que é uma técnica de coleta de dados que entende a linguagem como não neutra. Portanto, consiste na busca de sentido em uma narração, tendo como fim a reconstrução de acontecimentos sociais a partir da perspectiva das entrevistadas, tomadas como informantes (BAUER; GASKELL, 2003). As entrevistas foram registradas em áudio e transcritas na íntegra para uso no Atlas.ti, software que facilita a gestão de grande quantidade de textos. A metodologia de análise foi orientada pela Análise de Conteúdo, visando um estudo qualitativo que consiga compreender os atores sociais e suas crenças, atitudes, valores e motivações (BAUER; GASKELL, 2003, p. 65) e que permita "a interferência de conhecimentos relativos às condições de produção/recepção destas mensagens" (BARDIN, 2011, p. 42).

Além desta introdução, o artigo apresenta mais duas seções e as considerações finais. $\mathrm{Na}$ primeira seção, discorremos sobre a experiência escolar nas classes populares brasileiras e tocamos nos desdobramentos das juventudes nos contextos de pobreza, racismo e sexismo, a partir de dados que trazem panoramas gerais nacionais e das falas das nossas entrevistadas. Na segunda seção, apresentamos as características gerais das mulheres entrevistadas, seguindo de um debate sobre os impactos educacionais entre as adolescentes pobres que tiveram filha/o até os 19 anos de idade. Nas considerações finais, refletimos sobre os pontos propostos ao longo do artigo e podemos

\footnotetext{
${ }^{4}$ Fizemos um pequeno ajuste de 24 para 25 anos com a finalidade de ampliar um pouco mais os casos possíveis de análise.

5 Como resultado de aplicação desses critérios, não encontramos casos compatíveis na amostragem de entrevistas realizadas em Belo Horizonte, motivo pelo qual esta capital foi excluída da nossa subamostra.
} 
compreender sociologicamente a relação e o entrelaçamento entre esses dois fatores: experiência escolar e maternidade adolescente.

Este estudo tem o intuito de abarcar certa diversidade nas experiências juvenis e, para tanto, três categorias ganham relevo na análise: gênero, classe e raça/etnia. Essas categorias são interconectadas com base na abordagem das desigualdades interseccionadas (MARIANO; MACÊDO, 2015), de modo que sejam pensadas em suas múltiplas determinações e não como somatórias ou camadas separadas entre diferentes modos de opressão ou dominação (CRENSHAW, 1993).

\section{As desigualdades educacionais nas juventudes e a evasão escolar}

As adolescências estão marcadas pelo processo de escolarização e pelo modo como experenciam o acesso a esse direito. Enquanto no plano legal existem dispositivos que preveem a garantia do direito à educação para crianças e adolescentes, na prática social a situação se mostra diversa e esse direito é vivenciado distintamente de acordo com o pertencimento de classe, de raça e de gênero. $O$ analfabetismo, a defasagem entre série e idade e a evasão escolar são alguns dos indicadores que, no Brasil, evidenciam os problemas sociais relativos à educação. A evasão escolar é considerada um fracasso educacional em nossa sociedade, mas não só isso, há também grandes consequências individuais e sociais para as meninas e meninos que deixam o sistema de ensino (ZAGO, 2011, p. 64). Este fenômeno não está associado a um fator isolado, mas a um conjunto deles.

Com a expansão do acesso à escola no Brasil, a tendência foi de que ocorresse maior diversidade social na população que frequenta esse meio. Apesar disso, no Brasil, o preconceito e a discriminação racial estão entre os interferentes mais expressivos no direito à educação e ao rendimento escolar. Entre os adolescentes de 15 a 17 anos que frequentavam a escola, podemos dividir em duas categorias: o sexo e a cor ou raça. $76,4 \%$ das mulheres nessa faixa etária estavam na escola, enquanto entre os homens essa taxa foi de 66,7\% (IBGE, 2019). A diferença do acesso à educação para adolescentes brancas e negras é 
expressiva no país. O mundo do trabalho é também uma esfera social com vastas evidências das clivagens de raça/etnia e de gênero que vigoram no Brasil. Em estudo sobre juventude, ensino médio e processos de exclusão escolar, Dayrell e Jesus (2016) identificaram que jovens de famílias mais pobres entram mais cedo no mercado de trabalho. Dentre as adolescentes e jovens de 15 a 19 anos, 27,9\% disseram não frequentar a escola por motivos relacionados à entrada no mercado de trabalho e $23,3 \%$ afirmaram que precisavam cuidar dos afazeres domésticos e do cuidado de terceiros. Entre os rapazes, apenas $0,8 \%$ apresentaram o cuidado da casa ou de pessoas como fatores comprometedores para sua vida escolar (IBGE, 2019).

Percebe-se aqui os traços sexistas que envolvem a experiência educacional e profissional juvenis. Os meninos pobres têm a ocupação profissional como forte motivação para a desistência escolar e isso acontece tanto pela classe social em quem se encontram quanto por uma maior valorização masculina no mercado de trabalho. Por outro lado, o cuidado, como responsabilidade tradicionalmente atribuída às mulheres, torna-se um trabalho oculto, não contabilizado. Como afirmam Silvana Mariano e Márcio Souza (2015), as mulheres assumem gratuitamente as tarefas de bem-estar social que deviam ser garantidas pelos serviços públicos.

Como o gênero "é um padrão em nossos arranjos sociais, e as atividades do cotidiano são formatadas por esse padrão" (CONNEL; PEARSE, 2015, p. 47), as mulheres são responsabilizadas pelas tarefas que constituem o cuidar e, quando têm filhos, pela educação, saúde e criação destes/as, enquanto a participação do homem ainda é mais dirigida ao espaço público. Quando vão para o trabalho remunerado, adolescentes e mulheres são alocadas majoritariamente nas profissões associadas a funções de cuidado, como, por exemplo, professoras, empregadas domésticas, psicólogas e enfermeiras (SILVA; HALPERN; SILVA, 1999). Geralmente essas ocupações são mal remuneradas. Entre as mulheres pobres que têm filhos, um fator que agrava sua sobrecarga é a dificuldade, ou mesmo impossibiliadde, de acesso a vagas em creches e demais serviços de educação infantil em período 
integral. A escasses desses serviços impacta negativamente a vida das mulheres, e, portanto, suas possibilidades de escolaridade, desde a infância, pois muitas delas assumem ainda nesta fase da vida responsabilidades de cuidados de outras pessoas. Juliana, que tinha 25 anos no momento da entrevista e que é mãe desde os 19 anos de idade, nos relatou como a falta de creche é uma barreira para sua participação no trabalho pago. Conforme seu relato:

Eu acho que [o momento mais difícil da minha vida foi minha inserção no mercado de trabalho] quando eu tive meu primeiro filho... [...] foi bem difícil. Em questão de creche, de correr [atrás] de creche, dependendo da prefeitura, do Estado... foi bem difícil (Juliana, 25 anos, solteira, cursando Ensino Superior, 2 filhos, Porto Alegre).

Mariano e Souza (2015) argumentam que o cuidar dos filhos é comum no cotidiano de mulheres pobres e essa função é naturalizada como exclusivamente feminina, por meio de uma lógica orientada pelos papéis tradicionais de gênero, o que faz com que as mulheres assumam esse trabalho de forma gratuita. A associação entre cuidado e papéis femininos ocorre desde a infância, quando as meninas recebem atribuições familiares para cuidados de irmãs e irmãos, de outras crianças do grupo familiar ou da vizinhança e por vezes até como forma de trabalho infantil pago, quando elas são empregadas nesta ocupação nas chamadas "casas de família". Essa condição de assumir responsabilidades de cuidado desde a infância é mais pronunciada para as mulheres que são racializadas. Racismo e sexismo são combinações que produzem o fenômeno pelo qual as meninas, em especial as negras, se responsabilizam muito cedo pelos cuidados, abreviando a vivência das fases de infância e de juventude. De certo modo, essas meninas são precocemente inseridas nas responsabilidades associadas à vida adulta (SOUZA; MARIANO, 2018).

Vários/as autores/as, como Flávia V. Longo e Joice M. Vieira (2017), já registraram que demonstraram que a escolaridade da mãe é um fator crucial para as explicações das experiências escolares das crianças e das/os jovens. O tipo de experiência social e escolar da família 
e suas condições econômicas e culturais são importantes para nos ajudar a entender os motivos da evasão escolar, mas tais variantes não são mecânicas e deterministas. Deve-se considerar também a forma como o capital cultural é transmitido de mãe para filha/o e até mesmo a própria relação das meninas e meninos com o saber (ZAGO, 2011).

A síntese desse cenário brasileiro é que adolescentes e jovens vivendo em contextos de pobreza defrontam-se com múltiplas desvantagens em seus percursos educacionais e profissionais e gênero é um dos fatores intervenientes nessas trajetórias.

\section{Escolaridade e Maternidade Adolescente}

A socialização de papéis sociais distintos demarcados por gênero e raça implica em diferentes expectativas familiares e sociais em torno da escolaridade de meninos e meninas e esses contornos ficam mais bem definidos na adolescência. Quando considerado o recorte racial, transbordam as evidências das diferenças quanto às expectativas sociais para meninas brancas e meninas negras. Nesta seção, argumentamos que o nexo entre maternidade adolescente e abandono escolar é mais tênue do que o comumente suposto. A baixa escolaridade dessas mulheres jovens é fruto de um entrecruzamento de fatores que envolvem as próprias condições de desigualdades escolares e são acrescidas pela experiência da maternidade adolescente e não necessariamente produzida pela gravidez na adolescência.

O quadro a seguir apresenta as principais informações sobre as mulheres consideradas neste trabalho que compartilharam conosco suas narrativas sobre o tema em tela. 
Quadro 1 - Características gerais das mulheres que engravidaram na adolescência entrevistadas em Salvador, Porto Alegre, Belém, Brasília e São Paulo

\begin{tabular}{|c|c|c|c|c|c|c|c|c|}
\hline Nome & Idac & $\begin{array}{l}\text { Idade } \\
\text { que } \\
\text { teve } \\
\text { primeir } \\
\text { o filho }\end{array}$ & $\begin{array}{l}\text { Idade } \\
\text { que } \\
\text { iniciou o } \\
\text { trabalho } \\
\text { pago }\end{array}$ & $\begin{array}{l}\text { Escolar } \\
\text { idade }\end{array}$ & \begin{tabular}{|l|} 
Estado \\
Conjugal
\end{tabular} & $\begin{array}{l}\text { Quanti } \\
\text { dade } \\
\text { de } \\
\text { filhas/ } \\
\text { os }\end{array}$ & Cidade & Raça \\
\hline Isabela & 23 & 14 e 17 & 15 & \begin{tabular}{|l|} 
Ens. \\
Fund. \\
Incomp \\
leto
\end{tabular} & Casada & 3 & Salvador & Parda \\
\hline Jéssica & 25 & 17 & 16 & \begin{tabular}{|l} 
Ens. \\
Médio \\
Incomp \\
leto
\end{tabular} & Solteira & 2 & São Paulo & Parda \\
\hline Josiane & 20 & 19 & 15 & \begin{tabular}{l|} 
Ens. \\
Fund. \\
Compl \\
eto
\end{tabular} & $\begin{array}{l}\text { União } \\
\text { estável }\end{array}$ & 1 & Belém & Parda \\
\hline Juliana & 25 & 19 & 16 & \begin{tabular}{|l|} 
Ens. \\
Superio \\
$\mathrm{r}$ \\
Incomp \\
leto
\end{tabular} & Solteira & 2 & $\begin{array}{l}\text { Porto } \\
\text { Alegre }\end{array}$ & Branca \\
\hline Nilda & 17 & 16 & 15 & $\begin{array}{l}\text { Ens. } \\
\text { Fund. } \\
\text { Incomp } \\
\text { leto }\end{array}$ & Divorciad & 1 & Brasília & Parda \\
\hline Thamires & 25 & 17 e 18 & 11 & \begin{tabular}{l|} 
Ens. \\
Fund. \\
Compl \\
eto
\end{tabular} & Viúva & 3 & $\begin{array}{l}\text { Porto } \\
\text { Alegre }\end{array}$ & Negra \\
\hline
\end{tabular}

Fonte: base de dados da pesquisa "Gênero e Interseccionalidades na questão do desenvolvimento: os desafios do Programa Bolsa Família para a quebra do ciclo intergeracional da pobreza".

Isabela, com 23 anos, nasceu em Salvador e teve que deixar os estudos na $4^{a}$ série do Ensino Fundamental, para ajudar a família nas 
demandas de cuidado, demandas essas ampliadas quando, aos 14 anos de idade, ela teve seu primeiro filho. Na ocasião da gravidez ela deixou a casa de seus pais e foi morar com seu namorado, na casa da sua sogra.

Jéssica, com 25 anos, é de São Paulo e morou com sua mãe durante a infância. Ela relatou, na infância, experiências de trabalho entregando folhetos em vias públicas para ajudar sua mãe a sustentar os outros 9 filhos. Ela se recorda da escola como sendo uma boa aluna e parou de estudar aos 15 anos de idade, quando estava no primeiro ano do Ensino Médio. Sua motivação para o abandono escolar foi ter ido morar com seu namorado na época.

Josiane, com 20 anos, morou com sua mãe até os dois anos de idade e depois disso com sua avó paterna. Ela relatou que começou a trabalhar de babá e doméstica aos 15 anos de idade para ajudar com a renda da casa, já que sua avó ficou sem emprego. Relembrou que na escola tirava boas notas, mas que deixou de estudar no Ensino Fundamental e não conseguiu retornar porque engravidou. Ela espera terminar o Ensino Médio quando seu filho for maior e ela conseguir emprego.

Juliana, com 25 anos, nasceu em Porto Alegre e sempre associa sua presença no mercado de trabalho com o estudo. Ela engravidou aos 19 anos e no momento da entrevista estava cursando o Ensino Superior.

Nilda, com 17 anos, vive no Distrito Federal e foi criada por sua avó desde os dois meses de vida. Seu contato com a mãe é pequeno. Ela relatou uma infância difícil, segundo sua própria classificação. Parou de estudar no Ensino Fundamental I porque sua casa, em uma cidade do interior de Goiás, era distante da escola e isso lhe demandava um longo percurso de caminhada. Sua avó não tinha condições para lhes sustentar e, então, Nilda começou a trabalhar aos 15 anos de idade como faxineira e babá, trabalhos nos quais ela sentiu preconceito pela sua classe social.

A última é a Thamires, com 25 anos, nascida em um bairro pobre de Porto Alegre, onde continuava morando no momento da entrevista. Residiu com sua mãe até os 14 anos de idade. Ela falou sobre uma 
infância com privações, quando ela abandonou a escola na $5^{\mathrm{a}}$ série e começar a trabalhar no tráfico de drogas 6 .

No conjunto dessas histórias, percebemos que os impactos da gravidez e as motivações para o abandono ou continuidade dos estudos, como é o caso de Juliana, têm configurações diversas. O trabalho doméstico e o cuidado figuram como fatores de destaque entre as barreiras para a dedicação das meninas e adolescentes à escolarização. Essas são responsabilidades naturalizadas como tarefas exclusivamente femininas. As mulheres recebem incumbência de diversos trabalhos domésticos, em sua casa ou fora dela, e pelo cuidado de crianças, idosos/as e demais familiares. Segundo Munich Santana e Magda Dimenstein (2005), as mulheres de classe média e alta, que se dedicam a carreiras escolares ou profissionais, contratam trabalhadoras domésticas a quem delegam as funções anteriormente incumbidas a elas. Como mostram Silvana Mariano e Márcio Ferreira (2018), quando as mulheres mais pobres entram no mercado de trabalho, elas comumente lidam com a sobreposição entre as responsabilidades familiares e as decorrentes do trabalho pago. Como alternativa, em muitos casos, elas buscam ajuda em suas redes de apoio, quase sempre formada por mulheres próximas, como suas filhas, mãe e avós. Desse modo, as adolescentes em situação de pobreza na maioria das vezes têm em suas experiências o trabalho doméstico e de cuidado não pagos e pagos. Como revela o estudo "Por Ser Menina" $7,34,6 \%$ das meninas são responsáveis pelo cuidado de irmãos e irmãs e 67,6\% das estudantes de escola pública da zona urbana são trabalhadoras domésticas, essa taxa fica maior ainda nas zonas rurais (74,3\%) (PLAN, 2013). Se o recorte for realizado apenas para as camadas populares, tais taxas serão significativamente mais elevadas.

O trabalho doméstico em casa é uma aprendizagem para a atividade remunerada na casa de outras pessoas (SANTANA;

\footnotetext{
6 Para este trabalho não dispomos de condições para discutir o envolvimento das mulheres em situação de pobreza com o tráfico de drogas, o que tem sido crescente no Brasil nas últimas décadas.

7 Pesquisa realizada com meninas de 6 a 14 anos das cinco regiões do Brasil.
} 
DIMENSTEIN, 2005). Josiane, que foi inserida no trabalho pago aos 15 anos, como faxineira, com o objetivo de incrementar a renda da família, ilustra esse padrão e assim nos relatou:

Aos 15 anos eu comecei a trabalhar, para ajudar em casa. Porque teve um tempo [que a] minha [mãe] ficou sem trabalhar. Aí eu comecei [a] trabalhar para ajudar nas coisas de casa (Josiane, 20 anos, 1 filho/a).

A trajetória de Josiane converge com histórias de vida comuns entre as participantes da pesquisa. Thamires, uma das entrevistadas, que parou de estudar na $5^{\mathrm{a}}$ série porque trabalhava, nos relatou sua experiência de exploração com o trabalho doméstico pago:

Carteira assinada eu nunca tive. Mas já fiz uma faxina, já trabalhei numa casa de geriatria, de limpar. $\mathrm{Eu}$ trabalhei em algumas coisas, mas nunca de carteira assinada (Thamires, 25 anos, 3 filhos/as).

Nas histórias de vida que ouvimos dessas mulheres, percebemos que o trabalho remunerado é comumente um fator que precede a gravidez das adolescentes pobres e que leva à produção social do abandono escolar entre elas. Algumas relataram a responsabilidade por parte da renda familiar, como são os casos de Thamires e de Josiane, com o trabalho doméstico, e de Jéssica, que antes dos 16 anos começou a trabalhar com entrega de panfletos em vias públicas. Assim ela nos relata:

Primeiro trabalhei no farol entregando folheto, sempre tendo uma renda, né? Como minha mãe tinha 10 filhos, então eu me virava (Jéssica, 25 anos, 2 filhos/as).

A exemplo do que aconteceu nas experiências de outras entrevistadas, o relato de Thamires, que começou a trabalhar aos 11 anos, retrata como o trabalho na infância é obstáculo para a continuidade da vida escolar, conforme visualizamos no seguinte trecho:

[eu abandonei a escola] porque eu trabalhava; minha mãe nunca me deu sustento; eu trabalhava... ou 
achava o que fazer ou morria de fome dentro de casa. (Thamires, 25 anos, 3 filhos/as).

Segundo Maria de Fátima P. Alberto et al (2011), em estudo com crianças e jovens de 07 a 18 anos sobre o trabalho infantil doméstico e o processo de escolarização, o trabalho remunerado ou não, afeta a escolarização e leva à defasagem e à evasão escolar. Entre as 07 (sete) mulheres apresentadas, todas começaram a obter renda pelo trabalho antes dos 16 anos de idade.

O trabalho pago é o fator que mais destacado nas falas sobre evasão escolar entre essas mulheres. Não há falta de vontade para estudar, mas as condições de trabalho interferiram muito em suas trajetórias educacionais. Nilda, que foi inserida no trabalho pago aos 15 anos e que agora cursa Educação de Jovens Adultos para concluir a $7^{\mathrm{a}}$ série, exemplifica a vontade de estudar e de prolongar os estudos, no trecho a seguir:

Eu queria [voltar a estudar], sinceramente mesmo [...] terminar meus estudos [e] conseguir fazer uma faculdade para ter uma vida digna né, dar uma boa condição para minha filha (Nilda, 17 anos, 1 filha).

Além de viverem desvantagens educacionais pelo trabalho, as adolescentes das camadas pobres são vítimas da violência de gênero em outras esferas, dentre elas, em seu direito à educação sexual. Naiana Dapieve Patias (2014) demonstra que essas mulheres, por limitações financeiras, medo ou vergonha, são privadas de acesso aos métodos contraceptivos como o dispositivo intrauterino (DIU), injetáveis, preservativo feminino e contraceptivos de emergência, como a pílula do dia seguinte (PDS). Heilborn (2006) constata como as medidas adotadas pelo Brasil ainda são ineficientes:

As políticas de "prevenção da gravidez adolescente", ao invés de se centrarem sobre a normatização da sexualidade e da reprodução, deveriam contemplar uma discussão aberta sobre gênero e sexualidade, $o$ que possibilitaria um apoio aos jovens para uma entrada na vida sexual protegida de reprodução não prevista e das DSTs/Aids. Apoiar significa oferecer 
acesso a informações técnicas e assumir explicitamente a sexualidade adolescente e juvenil como legítima para os dois sexos (HEILBORN, 2006, p. 405-6).

Ela ainda explica como deveria ser a educação sexual:

A educação sexual [...] deve sobretudo dirigir-se à formação dos jovens para o relacionamento entre homens e mulheres e para o convívio com a diversidade, seja de cor/raça, cultura ou orientação sexual. Isso ressalta a importância da qualificação dos educadores no sentido de serem capazes de abordar esses temas desnaturalizando os estereótipos de gênero (HEILBORN, 2006, p. 408).

As barreiras para acesso à informação aos métodos contraceptivos aparecem na fala da Isabela, uma moça que passou pela experiência de gravidez aos 14 anos e nos contou que, por não ter conhecimento sobre preservativo ${ }^{8}$, engravidou novamente aos 17 anos:

Eu tive meu filho e tudo, aí foi. [...] [existia] esse negócio de preservativo e tudo, mas nesse tempo eu não sabia de nada, inocente, menina inocente [...] Aí foi que eu engravidei de novo (Isabela, 23 anos, casada, 3 filhos/as).

A maioria das participantes da pesquisa não apresentam reincidência de gravidez na adolescência, mas duas delas engravidaram uma segunda vez (Isabela e Thamires). Casos como esses são mais recorrentes entre as mulheres de classe popular (HEILBORN et al, 2002). A adoção de políticas públicas juvenis ineficientes para lidar com este tema perdura até hoje. Um exemplo disso é a campanha, de 2020, promovida pelo Ministério da Saúde em conjunto com o Ministério da Mulher, da Família e dos Direitos Humanos, que tinha como lema: "Adolescência primeiro, gravidez depois - tudo tem o seu tempo". A ministra Damares Alves recebeu muitas críticas ao recomendar a abstinência sexual juvenil como prevenção à gravidez.

\footnotetext{
${ }^{8}$ Não temos condições de aprofundar este tema no momento, mas, é sabido que o uso ou não de preservativos envolve fatores diversos para além do conhecimento e há forte carga moral e de desigualdades de gênero nessas práticas sexuais.
} 
Elaine R. Brandão e Maria Luiza Heilborn (2006) constataram que as adolescentes das classes pobres que engravidam passam por uma ruptura simbólica com a sua vida anterior, promovendo mudanças em seu núcleo doméstico, pois geralmente vão morar com o pai da sua filha ou filho. Nossa pesquisa corrobora esses achados. Segundo Rejane de Farias e Carmen Ojeda O. Moré (2012), em pesquisa com meninas em situação de vulnerabilidade de 10 a 14 anos, as exigências da maternidade provocam nas adolescentes e jovens pobres o sentimento de passagem para a vida adulta, diferente das camadas médias, em que a gravidez não muda de forma drástica o estatuto social da adolescente (BRANDÃO, 2006).

Diante do evento de uma gravidez, o núcleo familiar de adolescentes pobres muda. Com exceção de 1 entrevistada que já morava com o pai da sua filha, todas as participantes relataram que ao engravidar foram morar com o pai de sua filha ou filho, demonstrando uma ruptura simbólica com seu estatuto social anterior (BRANDÃO; HEILBORN, 2006). Essas mulheres, quando adolescentes, se depararam com um universo de novas responsabilidades que vieram junto com a gravidez. Exemplos disso são as falas Nilda, que engravidou aos 17 anos:

Quando a gente tem filho, a gente pensa em tudo que a gente vai fazer né, pensa primeiro nos filhos para depois fazer (Nilda, 21 anos, 1 filho/a).

A vida escolar pode sofrer interferências com a gravidez e a maternidade na adolescência, mas ela só apareceu como motivo para evasão em 1 dos casos das participantes. Isabela, que engravidou aos 14 anos e não voltou a estudar mais, não interpreta a gravidez como motivo central de desistência, mas sim a falta de redes de apoio que permitissem a conclusão de sua vida escolar:

[eu parei de estudar] porque eu engravidei e [...] tinha que olhar [meu] filho, entendeu? Aí eu ficava muito preocupada, assim, minha mãe sempre me apoiou em muitas coisas, mas ela acreditava [que] "quem pariu o Matheus que balance". Aí ficava muito puxado para mim (Isabela, 23 anos, 3 filhos/as). 
A recusa do pai dos seus filhos e filhas, por exemplo, fica evidente na fala dessas mulheres que, após a separação, não recebem contribuições financeiras e com o cuidado das crianças. Isso demonstra como, entre as famílias pobres, a rede feminina de apoio é sempre onde a solidariedade mais flui (VASCONCELOS, 2002). A fala de Thamires exemplifica o que foi dito e que também acontece com as outras mulheres, como no seguinte trecho:

Hoje em dia os pais deles [os filhos] não tem nenhum próximo a mim, não me ajuda. Pra mim também não faz diferença, se for me ajudar pra encher meu saco. Ah (Thamires, 25 anos, 3 filhos/as).

Considerando que a maternidade é uma responsabilidade social, o Estado deveria estar presente e garantir vagas em creches e demais serviços de educação infantil em período integral, de modo a facilitar que as mulheres conciliem vida familiar e trabalho pago (MARIANO; SOUZA, 2015). "No Brasil estima-se em 10 milhões o total de crianças em idade de frequentar creches, mas apenas $21 \%$ delas estão matriculadas em nestas (SORDI, 2012, p. 1409)". Juliana fala sobre isso nos seguintes trechos:

Quando ele [o filho] ainda [era] pequeno foi bem difícil, [ter que] correr [atrás] de creche, [ficar] dependendo da prefeitura, do Estado, foi bem difícil (Juliana, 25 anos, 2 filhos/as).

Nesta seção vimos que a discussão sobre gravidez e escolaridade não pode se isolar do contexto sociocultural que cerca a vida dessas adolescentes. Para isso, buscamos compreender algumas das dimensões da evasão escolar e da gravidez na adolescência.

\section{Considerações Finais}

A gravidez na adolescência assume, por vezes, lugar central nas discussões políticas, econômicas e sociais sobre evasão escolar. Esses debates são conduzidos de forma que dão a entender que a maternidade é uma responsabilidade exclusivamente feminina. Neste artigo, examinamos as experiências escolares, profissionais e de gravidez na 
adolescência de seis mulheres em situação de pobreza das cidades de Salvador, Porto Alegre, Belém, Distrito Federal e São Paulo. De modo sintético, concluímos que o abandono escolar antecede a experiência de gravidez e maternidade na adolescência, tendo esse episódio diversas motivações. O que mais percebemos nos relatos das participantes da pesquisa foram as condições desgastantes física e emocionalmente de trabalho, redes de apoio insuficientes para a continuidade do estudo, ausência de serviços públicos para cuidados infantis, falta de acesso a métodos contraceptivos, baixas expectativas quanto ao retorno da escolaridade e elevadas demandas de trabalho doméstico.

\section{Referências}

ALBERTO, Maria de Fátima Pereira; SANTOS, Denise Pereira; LEITE, Fernanda Moreira Leite; PESSOA, João. O trabalho infantil doméstico e o processo de escolarização. Psicologia E Sociedade, v. 23, n. 2, Florianópolis, p. 293-302, 2011.

BARDIN, Lawrence. Análise de conteúdo. São Paulo: Edição 70, 2011.

BAUER, Martin W., GASKELL, George. Entrevistas individuais e grupais. In: BAUER, M. W.; GASKELL, G. Pesquisa qualitativa com texto, imagem e som. 2 ed. Rio de Janeiro: Editora Vozes, 2003.

BRANDÃO, Elaine Reis, HEILBORN, Maria Luiza. Sexualidade e gravidez na adolescência entre jovens de camadas médias no Rio de Janeiro. Cadernos de Saúde Pública, v. 22, n.7, Rio de Janeiro, jul. 2006. Disponível em: http://www.scielo.br/pdf/csp/v22n7/07.pdf. Acesso em: 26 jan. 2020.

BRANDÃO, Elaine Reis. Gravidez na adolescência: um balanço bibliográfico. In: HEILBORN, Maria Luiza; AQUINO, Estela M. L; BOZON, Michel; KNAUTH, Daniela Riva. Aprendizado da sexualidade: reprodução e trajetórias sociais de jovens brasileiros. Rio de Janeiro: Fiocruz, 2006. p. 61-95.

BRASIL, Ministério da Saúde. Prevenção de gravidez na adolescência é tema de campanha nacional. Disponível em: https:/ / saude.gov.br/noticias/agencia-saude/46276-prevencao-de- 
gravidez-na-adolescencia-e-tema-de-campanha-nacional. Acesso em: 20 maio 2020.

BRASIL, Ministério da Saúde. Prevenção de gravidez na adolescência é tema de campanha nacional. Disponível em: https:/ / saude.gov.br/noticias/agencia-saude/46276-prevencao-degravidez-na-adolescencia-e-tema-de-campanha-nacional. Acesso em: 20 maio 2020.

BRASIL, Ministério da Saúde. Proteger e cuidar da saúde de adolescentes na atenção básica. Brasília: Ministério da Saúde, 2018.

CONNEL, Raewyn; PEARSE, Rebecca. A questão do gênero. In: CONNEL, Raewyn; PEARSE, Rebecca. Gênero: uma perspectiva global. São Paulo: Versos, 2015. p. 29-50.

CRENSHAW, Kimberle. Mapeando as Margens: Interseccionalidades, política de identidade e violência contra mulheres não-brancas. Stanford Law Reviwe, v. 43, 1993.

DAYRELL, Juarez Tarcísio; JESUS, Rodrigo Ednilson. Juventude, Ensino Médio e processos de exclusão escolar. Revista Educação $\mathcal{E}$ Sociedade, Campinas, v. 37, n. 135, p. 407-423, 2016

FARIAS, Rejane; MORÉ, Carmen Ojeda Ocampo. Repercussões da Gravidez em Adolescentes de 10 a 14 Anos em Contexto de Vulnerabilidade Social. Psicologia: reflexão e crítica, Porto Alegre, v. 25, n. 3, p. 596-604, 2012.

HEILBORN, Maria Luiza; AQUINO, Estela M. L; BOZON, Michel; KNAUTH, Daniela Riva. Aprendizado da sexualidade: reprodução e trajetórias sociais de jovens brasileiros. Rio de Janeiro: Fiocruz, 2006. p. 61-95.

HEILBORN, Maria Luiza; SALEM, Tania; ROHDEN, Fabíola; BRANDÃO, Elaine; KNAUTH, Daniela; VÍCTORA, Ceres; AQUINO, Estela; MCCALLUM, Cecília; BOZON, Michel. Aproximações socioantropológicas sobre a gravidez na adolescência. Horizontes Antropológicos, v. 8, n. 17, jun. 2002.

PLAN INTERNATIONAL BRASIL. Por ser menina no Brasil [resumo executivo]. Crescendo entre Direitos e Violências: Pesquisa com meninas de 6 a 14 anos nas cinco regiões do Brasil, Brasília, 2013. 
LONGO, Flávia Vitor; VIEIRA, Joice Melo. Educação da mãe para filho: fatores associados à mobilidade educacional no Brasil. Revista Educação E Sociedade, Campinas, v. 38, n. 141, p.1051-1071, 2017.

MARIANO, Silvana; SOUZA, Márcio Ferreira. Conciliação e tensões entre trabalho e família para mulheres titulares do Programa Bolsa Família. Revista Brasileira de Ciência Política, Brasília, n. 18, p.147-177, 2015. http://dx.doi.org/10.1590/0103-335220151806.

MARIANO, Silvana; MACÊDO, Márcia. Desigualdades e interseccionalidades: deslindando a complexa trama das hierarquias e agenciamentos. Mediações-Revista de Ciências Sociais, v. 20, n. 2, p. 1126, 2015. http://dx.doi.org/10.5433/2176-6665.2015v20n2p11.

MARIANO, Silvana. Políticas públicas e perspectiva de gênero: o enfrentamento recente das desigualdades de gênero no Brasil. In: MIGUEL, Luís Fellipe; BALLESTRIN, Luciana (Org.). Teoria e política feminista: contribuições ao debate sobre gênero no Brasil. Porto Alegre: Editora Zouk, 2020.

MARIANO, S; FERREIRA, L. P.; TAVARES, M. Em busca de si: construindo agência e autonomia feminina em contextos de pobreza. Simpósio Gênero e Políticas Públicas, VI., Londrina, 2020. Anais [...]. Londrina, 2020.

PATIAS, Naiana Dapieve; DIAS, Ana Cristina Garcia. Sexarca, informação e uso de métodos contraceptivos: comparação entre adolescentes. Psico-USF, v. 19, n. 1, 2014, p. 13-22. http:/ / dx.doi.org/10.1590/S1413-82712014000100003.

PROGRAMA DAS NAÇÕES UNIDAS. A verdadeira riqueza das nações: vias para o desenvolvimento humano. Washington D.C: Communications Development Incorporated, 2010.

SANTANA, Munich; DIMENSTEIN, Magda. Trabalho doméstico de adolescentes e reprodução das desiguais relações de gênero. PsicoUSF, v. 10, n. 1, p. 93-102, 2005.

SILVA, Cármen A. Duarte; HALPERN, Sílvia, C.; SILVA, Luciana A. Duarte. Meninas bem- comportadas, boas alunas; meninos inteligentes, indisciplinados. Cadernos de Pesquisa, v. 9, n. 107, p. 207225, 1999.

SOUZA, Márcio Ferreira; MARIANO, Silvana. Percepções de cuidado e práticas de gênero das mulheres beneficiárias do Programa Bolsa 
Família a partir de um recorte geracional: mudanças e permanências. Mediações-Revista de Ciências Sociais, v. 23, n. 3, p. 164-194, 2018. http:/ / dx.doi.org/10.5433/2176-6665.2018v23n3p164.

TILLMANN, Eduardo; COMIM, Flávio. Os determinantes da decisão entre estudo e trabalho dos jovens no Brasil e a geração nem-nem. Pesquisa e Planejamento Econômico, v.46, n.2, ago. 2016. Disponível em: http://ppe.ipea.gov.br/index.php/ppe/article/viewFile/1629/1225 . Acesso em: 21 abr. 2020.

VAISMAN, Fábio (Org). Estatuto da criança e do adolescente. Brasília, Edições Câmara, 2019.

VASCONCELOS, Pedro. Redes de apoio familiar e desigualdade social: estratégias de classe. Análise Social, Lisboa, v. 37, n. 163, p. 507-544, 2002.

ZAGO, Nadir. Fracasso e sucesso escolar no contexto das relações família e escola: questionamentos e tendências em sociologia da educação. Revista Luso-Brasileira, Rio de Janeiro, v. 2, n. 3, p.57-78, 2011. 